\title{
Psychometric Properties of Questionnaires for Assessing Chronotype
}

\author{
Somin Kim and Seog Ju Kim \\ Department of Psychiatry, Sungkyunkwan University School of Medicine, Samsung Medical Center, Seoul, Korea
}

\begin{abstract}
The valid measurement of chronotype is important since the construct has implications for our biological and psychological functioning. In the current review, we discuss the psychometric properties of the more frequently used chronotype measurements: the Morningness-Eveningness Questionnaire (MEQ), reduced Morningness-Eveningness Questionnaire (rMEQ), the Composite Scale of Morningness (CSM), Preferences Scale (PS), Munich ChronoType Questionnaire (MCTQ), and Morningness-Eveningness-Stability-Scale improved (MESSi). With regard to reliability, the MEQ, CSM, and PS have consistently showed high levels of reliability across different countries, whereas the reliability of the rMEQ has reported to be acceptable. In terms of validity, the MEQ, rMEQ, and CSM are highly correlated, which indicates that these scales share common aspects of chronotype. Though the MCTQ is highly correlated with the MEQ, the correlation becomes weaker as the MCTQ is corrected for sleep debt. Despite MESSi is a newly developed scale to measure circadian typology and amplitude, growing evidence supports MESSi as a reliable and valid instrument across different countries. Given that all of instruments commonly used to measure chronotype demonstrate good psychometric properties, it would be beneficial to consider which facet of chronotype (i.e., physiological or psychological) is the interest of researchers when conducting study concerning chronotype.
\end{abstract}

Key Words: Chronotype; Morningness-eveningness preference; Circadian typology; Circadian rhythm

Received: February 5, 2020 Accepted: February 29, 2020

Corresponding author: Seog Ju Kim, MD, PhD, Department of Psychiatry, Sungkyunkwan University School of Medicine, Samsung Medical Center, 81 Ilwon-ro, Gangnam-gu, Seoul 06351, Korea.

Tel: 82-2-3410-3583, Fax: 82-2-3410-0050, Email: ksj7126@skku.edu

@ This is an Open Access article distributed under the terms of the Creative Commons Attribution Non-Commercial License (https://creativecommons.org/licenses/by$\mathrm{nc/4.0)}$ which permits unrestricted non-commercial use, distribution, and reproduction in any medium, provided the original work is properly cited.

\section{INTRODUCTION}

The concept of chronotype refers to inter-individual differences for preferred time of day to be active or to sleep. Chronotype needs to be considered to lie on a continuum from extreme morning-types to extreme evening-types [1]. Morning-types (MT) go early to bed and wake up early, and perform at their best mental and physical performance in the early part of the day. In contrast, evening-types (ET) sleep and wake up late, and achieve their peak performance in the later of the day and evening hours. About $40 \%$ of adults fall in to one of the two extreme circadian types, whereas most people belong in the middle part of continuum [1]. Chronotype is also known as several different terminologies such as morningness-eveningness preference [2], circadian typology [3]. Chronotype can be measured by various self-administered questionnaires, which have been validated in many different languages.

Accurate measurement is essential in all academic fields. The importance of developing appropriate self-report instruments mea- suring chronotype is even greater, since the self-report instruments are most common tools for measuring chronotype. Though objective measurement of chronotypes (i.e., actigraphy, polysomnography) may also be available, these objective tools are not suitable for measuring long-term day-to-day variations of activity-rest-sleep rhythm [4]. Furthermore, objectively assessed activity cycle may not represent chrontypes correctly, since real life activity can be influenced by various social and occupational pressures besides chronotypes.

The aim of the current review is to review several commonly used self-report questionnaires that assess chronotype. In order to evaluate psychometric properties of the questionnaires, reliability and validity of questionnaires are discussed. In the current review, we concentrate on the more widely used instruments for assessing circadian rhythm. The questionnaires include the Morningness-Eveningness Questionnaire (MEQ) [5], the reduced MEQ (rMEQ) [6], the Composite Scale of Morningness (CSM) [7], the Preferences Scale (PS) [8], Munich ChronoType Questionnaire 
(MCTQ) [9], and Morningness-Eveningness-Stability-Scale improved (MESSi) [10].

\section{REVIEW OF CHRONOTYPE MEASURES}

\section{Morningness-Eveningness Questionnaire}

The development of the MEQ provided a self-administered chronotype scale that enables participants to report their preferred timing for sleep and wake, daily activity, and best timing for alertness. Responses to these items are thought to demonstrate individuals' underlying circadian function. Since its publication, the MEQ is one of the most widely used self-report chronotype scale. The MEQ consists of 19 items regarding sleep/wake times, preferred times for activities, and subjective alertness. The answer choices include a mix of multiple choice answers and using a visual analogue scale. The total score ranges from 16 to 86 and Horne and Östberg [5] initially predefined cutoff values as follows: definitely evening type: 16-30; moderately evening type: $31-41$; intermediate type: $42-58$; moderately morning type: 59-69; and definitely morning type: 70-86. However, Horne and Östberg [5] did not report the rationale for setting these cutoff values or dropping three items. In addition, they did not report the internal reliability of the scale. Furthermore, the initial study includes relatively small number of young adults $(\mathrm{n}=150)$. The small sample size and non-representativeness for other age have been criticized. Concerning that young adults is skewed towards eveningness [11], cutoff values should have been used with caution especially for other age groups.

A number of subsequent international studies have consistently found MEQ to be a reliable scale to assess chronotype. The internal reliability of the scale has ranged between 0.70 and 0.86 [3,12-18], and the stability of the scale is robust $(0.84-0.95)[14,17,19-21]$. Most of validation studies of the MEQ were administered to young adults [5,15,22,23], whereas Taillard et al. [24] validated the MEQ in middle-aged adults. Given that some studies suggest multidimensional nature of the MEQ [7,21], the use of a total score as an estimator of chronotype may be inappropriate [4].

The validity of the MEQ has been determined using both objective and subjective measures. Differences of MT and ET have been reported in the peak times of body temperature [20,22,25], cortisol release [20,25], sleep-wake habits [22]. In addition, MT and ET demonstrated significant differences in optimal time for performance and alertness [1,26].

The MEQ has earned other criticisms. First, the scale may be thought to be lengthy under certain circumstances. Some studies suggest that the significant portions of the variance can be explained by only few items. In particular, Adan and Almirall [6] reported that four items in the MEQ had weak discriminatory power. Zickar et al. [27] suggested MT items provide the best discrimination. Concerns over the factor structure of the MEQ underpinned the development of rMEQ [6].

\section{Reduced Morningness-Eveningness Questionnaire}

Adan and Almirall [6] selected five items $(1,7,10,18,19)$ from the
MEQ to develop a reduced scale. Because these five items address morning activity, rMEQ is considered a pure measure of MT [4]. By adding up the scores of all items, a total score ranging between 4 (extreme eveningness) to 25 (extreme morningness) can be obtained [6]. A number of studies reported that the rMEQ showed satisfactory psychometric properties and good convergent validity with the MEQ [28]. Natale et al. [29] reported that rMEQ could discriminate MT and ET based on motor activity records. More recently, Tonetti and Natale [30] found that rMEQ more clearly classify extreme chronotypes compared to the MEQ.

\section{Composite Scale of Morningness and the morning affect scale}

In order to develop a reliable and valid measure to eliminate the limitations of existing scales, Smith et al. [7] analyzed the items of the MEQ [5], the Diurnal Type Scale (DTS) [31], and the Circadian Type Questionnaire (CTQ) [32] using 501 North American students. They selected best items of each scale and incorporated them into a new scale called the CSM. The scale consists of the 13 items: nine from the MEQ and four from the DTS. A total score ranges between 13 (extreme eveningness) and 55 (extreme morningness). The response options include four or five multiple choices. The items address preferred times for sleep and wake, morning affect, and times for optimal cognitive performance.

The internal reliability of the CSM was 0.87 [7] and a number of subsequent studies have reported reliability greater than 0.80 [33]. The lowest coefficient was 0.65 obtained in Thailand [34]. This low statistic of Thailand version might be explained by difficulty of translating some items into Thai language and modifying the timing of daily activity based on the local activity timing. The stability of the CSM has been reported to be strong $(0.88-0.93)$ over 3 to 13-month period [11,35-37], suggesting chronotype as a stable behavioral trait.

With regard to convergent validity of the CSM, the CSM shows a strong correlation with the MEQ [35] and the $\mathrm{rMEQ}[38,39]$. The sensitivity of classification into the same chronotype was high both for the MEQ and for the rMEQ [38]. Construct validity of the CSM has been evaluated using subjective and objective measures. Several studies have reported that the CSM shows moderate correlations with self-reported sleep behavior on weekdays and weekend $[8,40,41]$. Using objective measure, Thun et al. [42] reported that the CSM is moderately correlated with sleep/wake times recorded on actigraphy.

In terms of distinguishing the chronotypes, Smith et al. [7] used a three-category classification, whereas Bohle et al. [40] suggested quartiles to classify MT and ET. However, both approaches may not be proper to use in cross-cultural studies since different sets of cutoff values have been reported by a number of studies $[7,38$, 43-45].

Several studies have explored the usefulness of developing a brief scale based on the CSM. Caci et al. [33] identified a five-item morning affect (MA) factor in a cross-cultural study of five countries, while Di Milia and Bohle [11] suggested a four-item model 
using a large student sample. The MA is a pure measure of morningness similar to rMEQ and its items do not refer to clock times of the day. In addition, the MA scale was found to be consistent across age or gender [4]. The internal reliability of the scale was 0.85 [46], and MT and ET demonstrated significant differences in subjective alertness during the day.

\section{The Preferences Scale}

There have been some limitations with regard to the rMEQ [6] and CSM [7]. Some items make permanent night workers difficult to respond since they assume all workers have a day-time schedule [4]. A second criticism is the use of the specific time period for daily activity. Since the timing of activity is known to be influenced by culture, these items may be inappropriate to use in cross-cultural studies [33]. The third limitation is the complication in response options of some items (e.g., mix of verbal and numerical responses) in rMEQ and CSM. The complexity of the scale may lead to response bias and influence the measurement properties of the scale [4].

The PS [8] was developed to overcome these limitations. The scale is composed of 12 items requiring participants to consider their behaviors relative to other people without asking specific time criteria for activity. Each item is responded using a 5-point scale and the total score can range from 12 to 60 , with higher scores indicating MT. Both classical and structural equation modeling analyses have shown that the psychometric properties of the PS are sound and comparable to an established self-report measurement of chronotype, the CSM. Across six countries, the internal reliability of the PS was reported to range between 0.80 and 0.90 [8]. Following studies also reported good internal reliability, but also found the weakness of two items [36,40,47]. The stability of the scale over a 3-month period was acceptable (0.77-0.92) [40,47]. However, Kripke et al. [48] found that most participants reported substantial overlap in sleep time, as the items of PS asks participants to compare themselves with "most people."

\section{Munich ChronoType Questionnaire}

The MCTQ [9] has been considered a relatively objective measure, since the scale deals with specific time to bed, sleep latency, and wake time. The MCTQ checked these times both for working days and free days. Most people tend to accumulate sleep debt during working days and compensate sleep on days off work. Considering the effect of sleep debt in working days on sleep-wake time in free days, the chronotype of the MCTQ is determined by MSFsc (the mid-point of sleep on free days corrected for sleep debt on workdays). The mid-point of sleep is considered the best marker for melatonin onset [49]. Several validation studies provide evidence that suggests MCTQ as a relatively objective measure of chronotype. The MCTQ was validated using more than 600 sleep diaries, actigraphy, and hormonal markers [50]. Juda et al. [51] modified the MCTQ in order to apply the scale to unique circumstances of shift workers and validated against sleep logs and actigraphy. Different from other instruments, the MCTQ does not provide a set of cutoff values. Instead, participants are classified as one of seven categories after completing the questionnaire.

Since the correlation of MCTQ with the MEQ is found to be 0.7 [52] and with the CSM about 0.5 to 0.6 [4], it is possible that the MCTQ and other instruments may assess different facets of chronotype. Thus, it would be useful to separate the biological indicator of chronotype with the more complicated, and possibly multi-dimensional, psychological facet of chronotype. Because the MCTQ is not rated on a Likert scale, internal reliability of the instrument cannot be evaluated.

\section{Morningness-Eveningness-Stability-Scale improved}

Given that some people shows fluctuations throughout the day, while others are more stable in their alertness and mood [53], Ogińska [54] and Dosseville et al. [55] proposed the amplitude (the range of diurnal changes in morningness-eveningness) as an additional measure of circadian rhythm. The distinctness (DI) scale was developed to evaluate subjective amplitude, indicating the subjective feeling of distinctness of daily changes $[54,55]$.

The MESSi [10] is the most recently developed self-report questionnaire of chronotype that improves previous chronotype instruments in a number of aspects: 1) MESSi is evolved out of several existing instruments; 2) the scale integrated the concept of amplitude; 3) items are updated to reflect energy feeling in the morning and in the evening; 4 ) it excludes items requiring specific clock times; 5) MESSi consists of a similar number of items referring to morningness and eveningness in order to avoid bias toward morning items; and 6) the scoring is balanced and the length of the questionnaire is relatively short.

The MESSi comprises items of CSM [7], Caen Chronotype Questionnaire [55], and Circadian Energy Scale [56]. Randler et al. [10] identified three subscales: 1) MA, 2) eveningness (EV), and 3) DI. The factor structure of the MESSi has been replicated across different countries [10,57-59]. The psychometric properties of the MESSi demonstrated that while internal reliability were all satisfactory/good, the DI scale showed the lowest level of internal reliability $[10,57,59,60]$. Convergent validity of the MESSi was supported by correlations with MEQ [61], rMEQ [57,59,60], and CSM [10,57].

\section{CONCLUSION}

The purpose of the current review was to evaluate the measurement properties of existing chronotype measures that are commonly used. The current review describes the psychometric properties and highlights limitations of each chronotype instruments. The current review may help researchers in the fields of chronobiology to choose most appropriate tools for their research.

Considering the measurements reviewed in this article have good psychometric properties, it would be beneficial to consider which facets of the chronotype (i.e., physiological or psychological marker) best represent the main objectives of the study. Other considerations when choosing a measurement of chronotype can 
be the aim of the study and the sample characteristics. In particular, original full scales (i.e., MEQ, CSM) tend to be used in laboratory settings, whereas short versions (i.e., $\mathrm{rMEQ}, \mathrm{MA}$ ) are more commonly used in large field studies for convenience.

We suggest several recommendations for future studies concerning chronotype. First, studies based on population-based samples with diverse geographic location are required, since environmental factors such as latitude [11,62], longitude [50,62], and exposure of light at birth [63] may influence chronotype. Second, future studies need to report their statistical results as well as the rationale for setting cutoff values. In particular, item-total correlations need to be reported in order to defend or delete any weak items [4]. Lastly, the quality of validation studies needs to be improved by including various subjective and objective data.

\section{Acknowledgments}

This study was supported by the Brain Research Program through the National Research Foundation of Korea, funded by the Ministry of Science, ICT \& Future Planning (No. 2016M3C7A1904336) and National Research Foundation of Korea (NRF) grant funded by the Korean government (MEST) (No. 2016R1A2B4011561).

\section{Conflicts of Interest}

The authors have no potential conflicts of interest to disclose.

\section{Author Contributions}

Conceptualization: Somin Kim, Seog Ju Kim. Data curation: Somin Kim, Seog Ju Kim. Formal analysis: Somin Kim. Funding acquisition: Seog Ju Kim. Investigation: Somin Kim. Methodology: Somin Kim. Project administration: Seog Ju Kim. Resources: Seog Ju Kim. Software: Seog Ju Kim. Supervision: Seog Ju Kim. Validation: Seog Ju Kim. Visualization: Seog Ju Kim. Writing—original draft: Somin Kim. Writing—-review \& editing: Seog Ju Kim.

\section{ORCID iDs}

Seog Ju Kim (1)

https://orcid.org/0000-0003-2467-5451

\section{REFERENCES}

1. Natale V, Cicogna P. Morningness-eveningness dimension: is it really a continuum? Pers Indiv Dif 2002;32:809-816.

2. Adan A, Archer SN, Hidalgo MP, Di Milia L, Natale V, Randler C. Circadian typology: a comprehensive review. Chronobiol Int 2012;29:1153-1175.

3. Adan A, Natale V. Gender differences in morningness-eveningness preference. Chronobiol Int 2002;19:709-720.

4. Di Milia L, Adan A, Natale V, Randler C. Reviewing the psychometric properties of contemporary circadian typology measures. Chronobiol Int 2013;30:1261-1271.

5. Horne JA, Ostberg O. A self-assessment questionnaire to determine morningness-eveningness in human circadian rhythms. Int J Chronobiol 1976;4: 97-110.

6. Adan A, Almirall H. Horne \& Östberg Morningness-Eveningness Questionnaire: a reduced scale. Pers Indiv Dif 1991;12:241-253.

7. Smith CS, Reilly C, Midkiff K. Evaluation of three circadian rhythm questionnaires with suggestions for an improved measure of morningness. J Appl Psychol 1989;74:728-738.
8. Smith CS, Folkard S, Schmieder RA, Parra LF, Spelten E, Almiral H, et al. Investigation of morning-evening orientation in six countries using the preferences scale. Pers Indiv Dif 2002;32:949-968.

9. Roenneberg T, Wirz-Justice A, Merrow M. Life between clocks: daily temporal patterns of human chronotypes. J Biol Rhythms 2003;18:80-90.

10. Randler C, Díaz-Morales JF, Rahafar A, Vollmer C. Morningness-eveningness and amplitude - development and validation of an improved composite scale to measure circadian preference and stability (MESSi). Chronobiol Int 2016;33:832-848.

11. Di Milia L, Bohle P. Morningness or morning affect? A short composite scale of morningness. Chronobiol Int 2009;26:494-509.

12. Chelminski I, Ferraro FR, Petros T, Plaud JJ. Horne and Ostberg questionnaire: a score distribution in a large sample of young adults. Per Indiv Dif 1997;23:647-652.

13. Chung MH, Chang FM, Yang CC, Kuo TB, Hsu N. Sleep quality and morningness-eveningness of shift nurses. J Clin Nurs 2009;18:279-284.

14. Larsen RJ. Individual differences in circadian activity rhythm and personality. Pers Indiv Dif 1985;6:305-311.

15. Lee JH, Kim SJ, Lee SY, Jang KH, Kim IS, Duffy JF. Reliability and validity of the Korean version of Morningness-Eveningness Questionnaire in adults aged 20-39 years. Chronobiol Int 2014;31:479-486.

16. Rhee MK, Lee HJ, Rex KM, Kripke DF. Evaluation of two circadian rhythm questionnaires for screening for the delayed sleep phase disorder. Psychiatry Investig 2012;9:236-244.

17. Pündük Z, Gür H, Ercan I. A reliability study of the Turkish version of the Morningness-Eveningness Questionnaire. Turk Psikiyatri Derg 2005;16:4045.

18. Treven Pišljar N, Štukovnik V, Zager Kocjan G, Dolenc-Groselj L. Validity and reliability of the Slovene version of the Morningness-Eveningness Questionnaire. Chronobiol Int 2019;36:1409-1417.

19. Agargun MY, Cilli AS, Boysan M, Selvi Y, Gulec M, Kara H. Turkish version of Morningness- Eveningness Questionnaire (MEQ). Sleep Hypn 2007;9:16-23.

20. Griefahn B, Künemund C, Bröde P, Mehnert P. The validity of a German version of the Morningness-Eveningness-Questionnaire developed by Horne and Östberg. Somnologie 2001;5:71-80.

21. Neubauer AC. Psychometric comparison of two circadian rhythm questionnaires and their relationship with personality. Pers Indiv Dif 1992;13: 125-131.

22. Ishihara K, Miyasita A, Inugami M, Fukuda K, Miyata Y. Differences in sleep-wake habits and EEG sleep variables between active morning and evening subjects. Sleep 1987;10:330-342.

23. Kerkhof GA, Van Dongen HP. Morning-type and evening-type individuals differ in the phase position of their endogenous circadian oscillator. Neurosci Lett 1996;218:153-156.

24. Taillard J, Philip P, Chastang JF, Bioulac B. Validation of Horne and Ostberg Morningness-Eveningness Questionnaire in a middle-aged population of French workers. J Biol Rhythms 2004;19:76-86.

25. Bailey SL, Heitkemper MM. Circadian rhythmicity of cortisol and body temperature: morningness-eveningness effects. Chronobiol Int 2001;18: 249-261.

26. Adan A. Influence of morningness-eveningness preference in the relationship between body temperature and performance: a diurnal study. Pers Indiv Dif 1991;12:1159-1169.

27. Zickar MJ, Russell SS, Smith CS, Bohle P, Tilley AJ. Evaluating two morningness scales with item response theory. Pers Indiv Dif 2002;33:11-24.

28. Young MW. Time travels: a 40-year journey from Drosophila's clock mutants to human circadian disorders (Nobel Lecture). Angew Chem Int Ed Engl 2018;57:11532-11539.

29. Natale V, Esposito MJ, Martoni M, Fabbri M. Validity of the reduced version of the Morningness-Eveningness Questionnaire. Sleep Biol Rhythms 2006;4:72-74.

30. Tonetti L, Natale V. Discrimination between extreme chronotypes using the full and reduced version of the Morningness-Eveningness Questionnaire. Chronobiol Int 2019;36:181-187.

31. Torsvall L, Akerstedt T. A diurnal type scale. Construction, consistency and validation in shift work. Scand J Work Environ Health 1980;6:283-290.

32. Folkard S, Monk TH, Lobban MC. Towards a predictive test of adjustment to shift work. Ergonomics 1979;22:79-91. 
33. Caci H, Adan A, Bohle P, Natale V, Pornpitakpan C, Tilley A. Transcultural properties of the composite scale of morningness: the relevance of the "morning affect" factor. Chronobiol Int 2005;22:523-540.

34. Pornpitakpan C. Psychometric properties of the composite scale of morningness: a shortened version. Pers Indiv Dif 1998;25:699-709.

35. Greenwood KM. Long-term stability and psychometric properties of the Composite Scale of Morningness. Ergonomics 1994;37:377-383.

36. Gil E, Abdo PL, Rodríguez M, Zanín L, De Bortoli M. Psychometric and comparative study of an Argentine version of the morningness composite and the early/late preference scales. Chronobiol Int 2008;25:133-143.

37. Caci H, Nadalet L, Staccini P, Myquel M, Boyer P. The composite scale of morningness: further psychometric properties and temporal stability. Eur Psychiatry 2000;15:278-281.

38. Caci H, Deschaux O, Adan A, Natale V. Comparing three morningness scales: age and gender effects, structure and cut-off criteria. Sleep Med 2009;10:240-245.

39. Randler C. German version of the reduced Morningness-Eveningness Questionnaire (rMEQ). Biol Rhythm Res 2013;44:730-736.

40. Bohle P, Tilley AJ, Brown S. Psychometric evaluation of the Early/Late Preferences Scale. Ergonomics 2001;44:887-900.

41. Caci H, Nadalet L, Staccini P, Myquel M, Boyer P. Psychometric properties of the French version of the composite scale of morningness in adults. Eur Psychiatry 1999;14:284-290.

42. Thun E, Bjorvatn B, Osland T, Steen VM, Sivertsen B, Johansen T, et al. An actigraphic validation study of seven morningness-eveningness inventories. Eur Psychol 2012;17:222-230.

43. Adan A, Caci H, Prat G. Reliability of the Spanish version of the Composite Scale of Morningness. Eur Psychiatry 2005;20:503-509.

44. Randler C. Validation of the full and reduced Composite Scale of Morningness. Biol Rhythm Res 2009;40:413-423.

45. Alzani A. A tool for assessing individual differences in circadian rhythms: an Italian version of the Composite Scale of Morningness. Testing Psicometria Metodologia 1998;5:19-31.

46. Di Milia L, Muller H. Does impression management impact the relationship between morningness-eveningness and self-rated sleepiness? Pers IndIv Dif 2012;52:702-706.

47. Di Milia L. A psychometric evaluation and validation of the Preferences Scale. Chronobiol Int 2005;22:679-693.

48. Kripke DF, Rex KM, Ancoli-Israel S, Nievergelt CM, Klimecki W, Kelsoe JR. Delayed sleep phase cases and controls. J Circadian Rhythms 2008;6:6.

49. Terman JS, Terman M, Lo ES, Cooper TB. Circadian time of morning light administration and therapeutic response in winter depression. Arch Gen
Psychiatry 2001;58:69-75.

50. Roenneberg T, Kuehnle T, Juda M, Kantermann T, Allebrandt K, Gordijn M, et al. Epidemiology of the human circadian clock. Sleep Med Rev 2007; 11:429-438.

51. Juda M, Vetter C, Roenneberg T. The Munich ChronoType Questionnaire for shift-workers (MCTQShift). J Biol Rhythms 2013;28:130-140.

52. Zavada A, Gordijn MC, Beersma DG, Daan S, Roenneberg T. Comparison of the Munich Chronotype Questionnaire with the Horne-Ostberg's Morningness-Eveningness score. Chronobiol Int 2005;22:267-278.

53. Murray G, Nicholas CL, Kleiman J, Dwyer R, Carrington MJ, Allen NB, et al. Nature's clocks and human mood: the circadian system modulates reward motivation. Emotion 2009;9:705-716.

54. Ogińska H. Can you feel the rhythm? A short questionnaire to describe two dimensions of chronotype. Pers Indiv Dif 2011;50:1039-1043.

55. Dosseville F, Laborde S, Lericollais R. Validation of a chronotype questionnaire including an amplitude dimension. Chronobiol Int 2013;30:639-648.

56. Ottoni GL, Antoniolli E, Lara DR. The Circadian Energy Scale (CIRENS): two simple questions for a reliable chronotype measurement based on energy. Chronobiol Int 2011;28:229-237.

57. Díaz-Morales JF, Randler C, Arrona-Palacios A, Adan A. Validation of the MESSi among adult workers and young students: general health and personality correlates. Chronobiol Int 2017;34:1288-1299.

58. Tomažič I, Randler C. Slovenian adaptation of the Morningness-EveningnessStability Scales improved (MESSi). Biol Rhythm Res 2018 Oct 14 [Epub]. Available at: https://doi.org/10.1080/09291016.2018.1535539.

59. Carciofo R, Song N. The Chinese Morningness-Eveningness-Stability-Scale improved (MESSi): validity, reliability, and associations with sleep quality, personality, affect and life satisfaction. Chronobiol Int 2019;36:1036-1046.

60. Faßl C, Quante M, Mariani S, Randler C. Preliminary findings for the validity of the Morningness-Eveningness-Stability Scale improved (MESSi): correlations with activity levels and personality. Chronobiol Int 2019;36: 135-142.

61. Rodrigues PFS, Vagos P, Pandeirada JNS, Marinho PI, Randler C, Silva CF. Initial psychometric characterization for the Portuguese version of the Morningness-Eveningness-Stability-Scale improved (MESSi). Chronobiol Int 2018;35:1608-1618.

62. Randler C. Differences in sleep and circadian preference between Eastern and Western German adolescents. Chronobiol Int 2008;25:565-575.

63. Natale V, Di Milia L. Season of birth and morningness: comparison between the northern and southern hemispheres. Chronobiol Int 2011;28: 727-730. 